\title{
A STUDY ON THE DEVELOPMENT AND SANITATION PROFILE OF SMART CITIES - A CASE STUDY OF TIRUCHIRAPALLI CITY
}

\author{
Subham Kharel ${ }^{1,}$, Mohammed Jaffer Shariff ${ }^{1}$, Sudha Ravindranath ${ }^{1}$, Vidya A ${ }^{1}$, K. Ganesha Raj $^{1}$ \\ Regional Remote Sensing Centre-South, Indian Space Research Organization, Bengaluru, India - kharelsubham1@gmail.com
}

Commission V, SS: Infrastructure and Development Planning

\begin{abstract}
:
Health and Sanitation are the two major limbs that support Swachh Bharat Abhiyaan. This scheme was launched by the Indian Government targeting towards achieving a more clean and healthy India. The present study was done for estimating the cleanliness and development of Tiruchirapalli city located in the state of Tamil Nadu. Geospatial \& Statistical tools were used for analyzing and ranking different wards. Panchromatic \& MSS merged image and ancillary data obtained from Trichy Municipal Corporation was used to derive necessary GIS layers. Adequacy of the public toilets for each ward was found out using spatial layers and mathematical equation derived from census and sanitation data. Development Index was generated for each ward giving appropriate ranking by considering parameters such as public toilets, population, built-up densities and NDVI for each ward. The results were used for estimating the adequacy of public toilets in each ward and deciding the best wards based on ranks obtained from weighted values of different developmental parameters.
\end{abstract}

Keywords: Swachh Bharat Abhiyaan, Public toilets, Statistics, Development Index, Adequacy, NDVI

\section{INTRODUCTION}

Mahatma Gandhi had given much importance to Sanitation and it was his dream to make India a clean and developed Country. Swachh Bharat Abhiyaan is being carried out by the Quality Council of India in collaboration with the Ministry of Urban development in which an extensive sanitation survey was done across various cities of the country in order to analyze the effect, impact and progress of Swachh Bharat Mission for establishing a level of competitiveness amongst selected cities all over the country. It is run by the Government of India to fulfill the vision of the Father of the Indian Nation, 'Mahatma Gandhi' by taking the help of all communities of people specialized in different sectors to make it a global success. The mission has to be completed by the $150^{\text {th }}$ birth anniversary of the Father of the Nation $\left(2^{\text {nd }}\right.$ October of 2019). The mission covers all rural and urban sectors of India under guidance of the Urban Development and Drinking Water and Sanitation ministries accordingly. Trichy was awarded the cleanest city award in the year 2017.

\subsection{PROFILE OF THE STUDY AREA}

Tiruchirappalli famously known as Trichy, is a Swachh Bharat City in the Indian state of Tamil Nadu which is the administrative headquarters of Tiruchirappalli District. Tiruchirappalli is the third and fourth largest city by area and population in the state as per census 2011. Trichy lies in between 10.73644 to 10.89534 North latitudes and 78.615 to 78.762 East longitudes. It has the fourth largest Municipality and urban agglomeration in the state of Tamil Nadu.

\footnotetext{
* Corresponding author
}

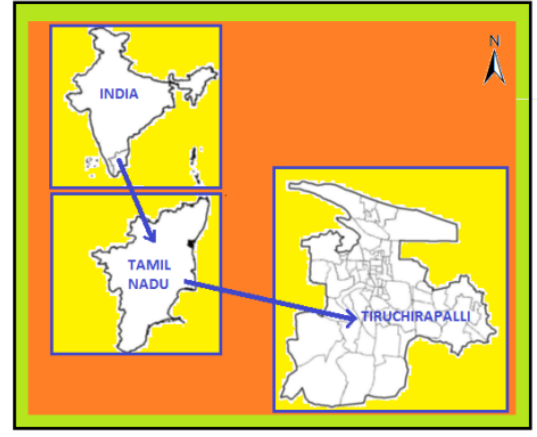

Figure 1: Location Map of Tiruchirappalli (Trichy)

All the water needs in Trichy is fulfilled from Cauvery river that flows in the northern part of the city; where it branches out into two rivers and again joins at a distance forming the world known island of Srirangam which is incorporated into the Tiruchirappalli City Municipal Corporation lately. The city is home to 916,857 people and occupies over 167.23 square kilometers as per 2011 census. The most prominent historical monuments in Tiruchirappalli are the Rockfort, Ranganathaswamy temple and the Jambukeswarar temple.

\subsection{RESEARCH QUESTIONS}

The aim of this study is to find the adequacy of sanitary facilities by taking into consideration public toilet information, its impact on Swach Bharat Abhiyaan and monitoring the development of wards with the help of ranks which are assigned using python coding. Analysis was done for 65 wards of Trichy through statistical evaluation of selected wards by taking into consideration parameters such as greenery, households, population, population density, ward 
area and public toilet. Keeping in mind the above targets, following research questions have been set for the study:-

1. Does the city of Trichy have adequate sanitary facilities?

2. Can Trichy be considered as a Swachh Bharat City in true sense?

3. What is the current scenario of development in Trichy?

\subsection{RELATED WORK}

1. Tiwari (2014) et.al [1] studied the objectives of Swachh Bharat Abhyaan. The study focused on the level of awareness of the Swachh Bharat Mission and Swachh Vidyalaya in the middle school students of public and private schools.

2 Evne (2014) et.al [2] also studied the objectives of Swachh Bharat Mission. The study basically focused on the impact of Swachh Bharat Abhiyaan on the Dalit Community of the country. The authors concluded that it is the responsibility of every citizen of the country to be clean and have a well maintained hygiene. Each person should think of progress rather than wait for government to take initiatives.

3 Badra and Sharma (2015) et.al [3] studied the impact of Swachh Bharat Campaign. The study also suggested the measures boost the participation and effectiveness of Swachh Bharat Mission. The study reported that teamwork and patriotism are necessary to make India green and clean. The involvement of celebrities in their respective neighbourhood will initiate and give more boost to the drive.

4 Rao and Subbarao (2015) et.al [4] studied the impact and development caused due to Swachh Bharat Abhiyaan. The work basically focussed on Gandhian concept of sanitation. After evaluation, conclusions were made which showed the opportunity and responsibility of the different people living in the society to declare their campaign against open defecation and waste disposal by simply reporting the instances of manual scavenging.

5 Thakkar (2015) et.al [5] conducted his research on objective, merits and importance of Swachh Bharat Abhiyaan. The study focused on the impact of Swachh Bharat Abhiyaan on health as well as education sectors. After the study, the author came to a conclusion that the mission of Clean India or Green India is an appreciable step the government of India which is improving sanitation and development of cities. Sustainable Revolution began in the time 1960s -1970s. It all started with a movement which emerged in 1980's but was at full-fledged condition in the early 1990's. Ecological awareness was improvised initially by an Rachel Carson "American writer and naturalist" and other environmentalists. The first earth day attracted 20 million people and educated them about the impact of industrialisation on man and environment.
6 Munier. S (2005) et.al [6] derived from his studies that Sustainability Revolution has evolved into a diverse, world-wide, multi-cultural and a visionary revolution, which focused on the 3E's simultaneously leading to a positive response from both within and amongst people of the society. Ecology \& Environment, Economy \&Employment, Equity \& Equality, all components of the $3 E$ 's are necessary in establishing sustainable development, since it provides us with a strategy to update humans from practising resources without sustaining them to a global relationship with nature that modifies not only the relationship of man with earth and its biodiversity but also structures of values required to integrate issues related to ecology and economics.

7 Earth 911. Trash Planet: India (2009) et.al [7] in their study found out that Ecological and Environmental sustenance is necessary for the existence of man. Environmental sustenance includes sustainable use of air, heating, water, cooling and food which is safe to eat. If this continues to happen, then it will increase the chances of ecological crisis such as depletion of water bodies due to overfishing, deforestation and pollution of land and forest area by clear-cutting and depleting fresh water bodies by addition of toxins and pollutants. Secondly, economic and employment sustenance is necessary to create a long term employment but not by pressurizing the ecosystem. Haw ken, Amory and Hunter quoted that "natural capital, made up of resources, living systems and ecosystem services" is an essential factor influencing economic development giving more priorities to human, financial and capital resources. Thirdly, equity and equality sustenance is needed for the community as a whole taking into view ecological as well as economic development for a long term. It describes the well-being of the individual and community, both of which are dependent on each other. Equal distribution of resources shall be ensured for establishing long term sustenance of the society. However, almost every human activity generates some type of waste matter. There is an increase in waste generation when a country develops in all respects namely social, economic, technical, industrial, urban and population growth.

8 Singh. K. in The CSR Journal et.al [8] has observed during his research that waste generated in India approximately for one person is 1.3 pounds per day which is relatively low when compared to 4.6 pounds of waste generated by a person in the United States per day. These statistics are of 2009 July when U.S. population versus India's population was in the ratio of 1:4. U.S. population then was 307 million whereas India had 1.2 billion people residing. These statistics imply that Indians could generate as more as 27 million tons more waste than U.S. per year. The problem had been boosted by India's rapid population growth. 
9 Growth of urban population is recorded approximately at a rate of 20 per cent per year since 1980's and the projected statistics shows that it can be incremented by 10 per cent or more by the end of 2015. The nation's waste management scheme which is poorly organized is continuing to increase irreversible damage to the environment and serious health problems. The, industry and government need to work together to make major improvements.

10 Clean India Journal Creating Cleanliness et.al [9] Prime Minister of India, Mr. Narendra Damodhar Modi had officially launched this campaign on the birthday of the father of the nation "2 October 2014" at New Delhi. He participated in road cleaning activities too. Participation of about 3 million people of India from different communities, religion, race, caste, creed and gender was witnessed during the event. It was India's biggest ever Swach Bharat drive. The modules of the programme are:

a) Construction of individual sanitary latrines for households below the poverty line with $80 \%$ subsidy was to be carried out in areas of major demands as mentioned above.

b) Replacement of dry latrines with low-cost sanitary latrines.

c) Exclusively large sanitary complexes to be constructed for women in villages installed with facilities such as hand pumping, bathing, sanitation and washing.

d) Building up of sanitary marts.

e) Overall sanitation of village areas by construction of soakage pits, drains, and proper solid \& liquid waste disposal.

f) Awareness in people about maintenance of health and proper sanitation facilities and their cleanliness for maintaining good household, personal and environmental sanitation.

11 Phukan. S.R (Sep, 2014) et.al [11] in their research studied about Swachh Bharat and concluded that Swachh Bharat Abhiyaan is having the potential to contribute to GDP growth, provide employment and reduce health ailments, hereby connecting an economic activity. Cleanliness is connected to tourism and global interests of the country. India's top 50 tourist destinations displayed highest standard of hygiene and cleanliness needs to be changed to achieve the global perception of cleanliness and safety.

12 Sharma. Y (Feb, 2015) et.al [12] conducted a study on Swachh Bharat Abhiyaan and derived that Clean India can bring more tourists, thereby increasing revenue generation. The author appeals people to devote 100 hours every year for cleanliness. The sanitation program, solid waste management and waste water management must be implemented to make Swachh Bharat Abhiyaan achieve a major milestone.
The author then suggested for provision of separate toilet facilities for boys and girls in every school in the country by 15 August, 2015. According to data available from Government sources from 2015, 7.1 lakh individual household toilets have already been built under this scheme. 31.83 lakh individual toilets have already been completed by 2015 . Today, Karnataka achieved $61 \%$ of the target while Punjab achieved only about $5 \%$ of the target.

13 Coates. S and Dulk. D.C (Nov, 2014) et.al [13] studied about Swachh Bharat Abhiyaan and reported that the Government of India modified the Comprehensive Rural Sanitation Program and has launched Total Sanitation Campaign (TSC).

To boost the Total Sanitation Campaign, the government of India launched a scheme in the form of awards for total sanitation coverage, maintenance and open defecation-free villages, blocks \& districts which was named Nirmal Gram Puraskar. Effective since 1 April 2012, the TSC was renamed as Nirmal Bharat Abhiyaan (SBA). 2 October 2014 witnessed this campaign as a Swachh Bharat Mission.

14 Gharse and Sharma et.al [14] in their paper entitled "Gandhi's Views on youth as an agent for social transformation" vocalized Gandhi's dream of building a healthy and clean nation. Gandhi dreamt of social transformation on a priority basis which is no less than a new revolution. Long term basic changes and some outward changes are necessary. Mass public cleansing and Government action is the only key to achieve this change in which the youth should be the catalysts for the change. The entire system needs energetic and young people who will be playing instrumental roles.

15 14. Hari Pulakkat et.al [15] in his article titled Swachh Bharat Abhiyaan: Why cleaning up India is serious business stated that as Swachh Bharat Abhiyaan basically focussed on sanitation and solid waste management. Cleaning India takes far more time, as invisible pollutants work their way through our ecosystem and food chain.

Further he reported that all environmental scientists as well as engineers are not bothered about cleaning up the country. He reported that it is serious problem, and it costs major behavioural improvements as well as high expertise as well as scientific knowledge about biology, ecosystems and the environment. He reported that waste management is one of the major challenges needed to be taken up by Indian Government and scientists.

\section{MATERIALS AND METHODS}

\subsection{DATA COLLECTION}

\subsubsection{Satellite Images}


CartoSat-2S data was used during the course of the study which include the following two datasets which as=re displayed in Figure 2:-

a. PAN (Panchromatic Camera with $0.6 \mathrm{~m}$ spatial
resolution),

b. HRMX (Multi spectral camera with $1.6 \mathrm{~m}$ spatial resolution)

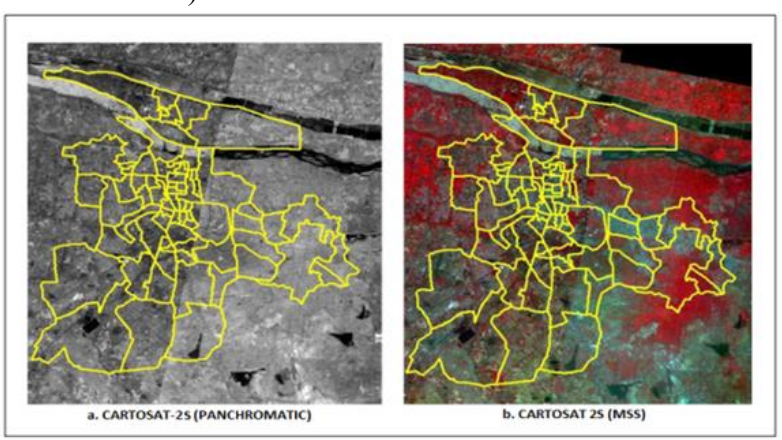

Figure 2: Satellite Images used during the study

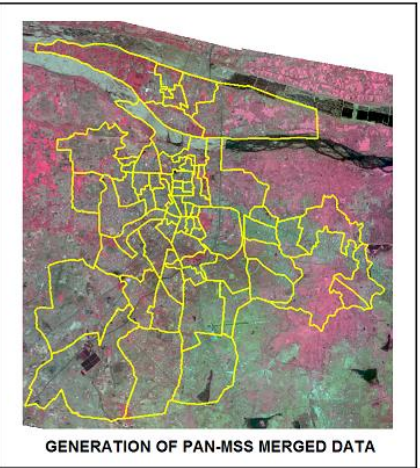

Figure 3: Panchromatic-MSS Merge dataset

\subsubsection{Ancillary Data Obtained From Trichy Municipal} Corporation

1. Population data from Census Report for 2001, 2011 and 2015 for each

2. Ward Boundary and toilet Locations

3. Solid Waste Management data

\subsection{RESEARCH METHODOLOGY}

\subsubsection{GIS Database Generation}

Satellite data analysis yielded the built-up, NDVI, updated transportation network, surface water bodies, drainages, slope, and geomorphology layers. Shape files for different layers including available layers from earlier project were brought to a standardized projection and data was made ready for analysis displayed in Figure 4. The legacy data that was derived using GIS platform that were used for the analysis are listed as below:

a. Ward Boundary

b. Layers such as geomorphology, slope, settlements, soil etc.

c. Normalized Difference Vegetation Index (NDVI) d. Water body features including rivers and lakes.

e. Transportation Network which includes road and rail network

f. Land use Land cover layers

g. Toilet layers

All layers mentioned above were at a different orientation which was spatially adjusted later using high resolution image and Arc GIS spatial adjustment tools.
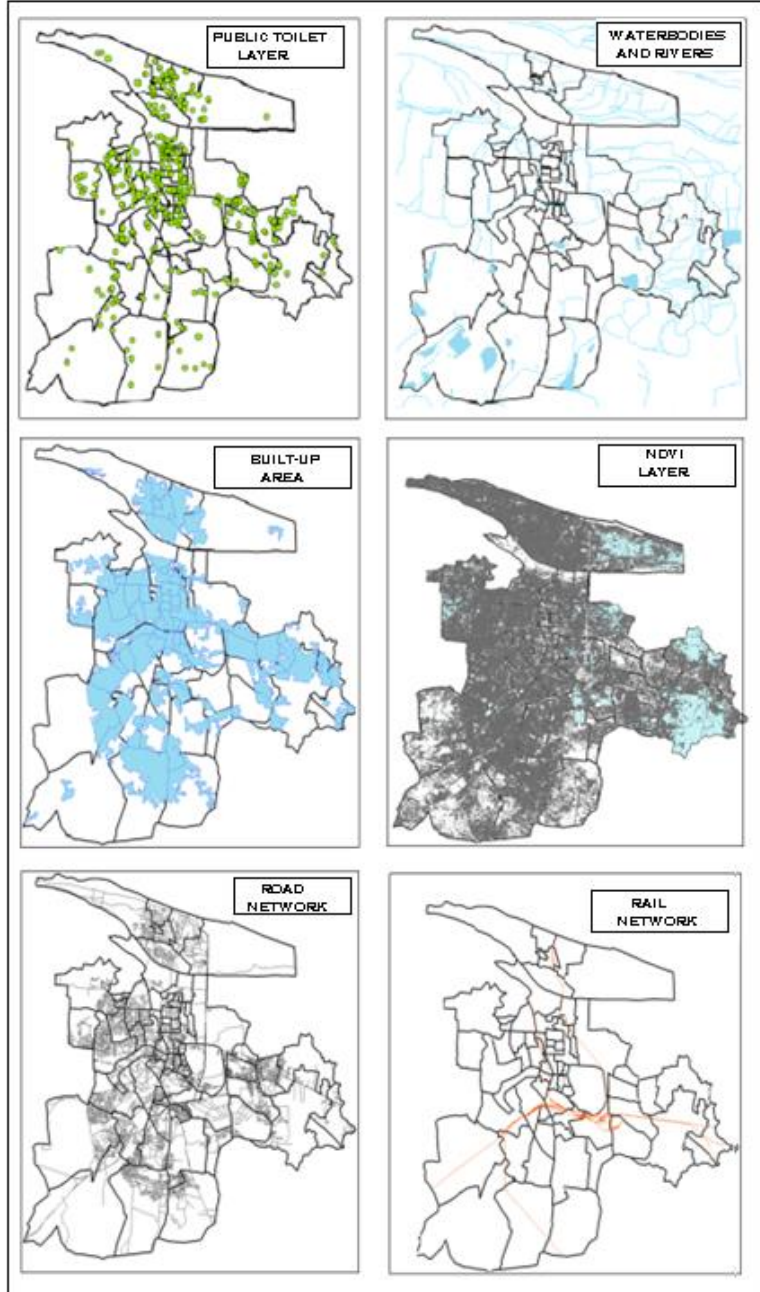

Figure 4: GIS Layers; a: Public Toilets; b: Rivers and water bodies; c: Road Network; d: Built-up Area; e: NDVI; f: Rail Network

\subsubsection{Adequacy of Public Toilets}

The required number of toilets in each zone was calculated using the formula shown below:

1. One toilet was estimated for 1000 people per day. Hence,

\section{Number of Toilets based on population}

$$
\text { (T1) }=\frac{\text { Recent Population }}{1000}
$$


2. The number of public toilets were incremented by $10 \%$ in regions where parks and temples were present, i.e. T2 which is shown below:

Incremented toilets due to presence of parks and temples

$$
\text { (T2) }=\frac{10 \text { X T1 }}{100}
$$

3. Since one household consists of an average of four members, Household to DU ratio was calculated to know how many extra people are residing in the city which was expressed using the following expression:

No. of Toilets as per Dwelling Units requirements

$$
(T 3)=\frac{\left(\frac{\text { RecentPopulation }}{4}\right)-\text { HH }}{250}
$$

4. All slum areas were identified and an increment of one toilet was assigned to each slum area shown by the equation below:

\section{No. of Required Toilets in slum areas}

(T4) =A minimum of 5 toilets based on GIS Area-----(iv)

5. Therefore the total projected toilets to be built was calculated by the following expression:

\section{Total Projected Public Toilets}

$(T)=T 1+T 2+T 3+T 4------(v)$

After all of the above calculations, the following records were generated which represent the toilets that are already existing, the requirement based on increased population and forecasts based on tourism and slum requirements.

6. Rankings were based on priorities thereafter.

\subsubsection{Tabulation of data to derive inputs for Development Index}

Quantitative analysis was carried out on collective primary and secondary data using ranking method. The data obtained/generated was initially given ranks for proper classification. In order to make the above ranked data unbiased, a classification methodology was adopted which is explained in the statements that follow. Weights for different wards were given on the following basis and priorities.

1. The data was classified under three categories namely CENSUS, INFRASTRUCTURE and SATELLITE DATABASE :

a. Population in 2015, population density and households were grouped under CENSUS data category.

b. Road length and toilets were grouped under the INFRASTRUCTURE category.

c. Percentage built-up and NDVI areas were grouped under SATELLITE DATABASE category.
2. Integrated parameters such as $\mathrm{V}_{\mathrm{P}}, \mathrm{V}_{\mathrm{i}}$. and $\mathrm{V}_{\mathrm{s}}$ were obtained for population, infrastructure and satellite database simultaneously.

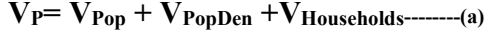

$$
\begin{aligned}
& V_{i}=V_{\text {Roads }}+V_{\text {toilets-a-no }}
\end{aligned}
$$

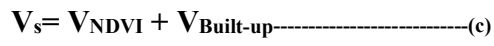

$V_{P}=$ Population, $V_{I}$ - infrastructure, $V_{s}=$ Satellite Data Parameters, $V_{P o p}=$ Population, $V_{P o p D e n}$ Population Density , $V_{\text {Households }}=$ Households,$V_{R}=$ Roads, $V_{\text {toilets }}$ - Toilets, $V_{\text {NDVI }}=$ NDVI,$V_{\text {Built-up }}$ Built-up

3. After categorization of the data, normalized indexes were used to remove any kind of biasness in the data. Below are the equations generated and utilized for obtaining the normalized indexes:

Normalized $V_{P}=V_{P} / 12$

Normalized $V_{i}=V_{i} / 8$

Normalized $V_{s}=V_{s} / 8$

Normalized $V_{p}=$ Normalized Population data , Normalized $V_{1}=$ Normalized Infrastructure data , Normalized $V_{S}=$ Normalized Satellite dat

4. All the normalized indexes obtained were multiplied with ranks allotted to each parameters mentioned above like Population, Population Density, Toilets and NDVI (depending upon the necessity/use of the parameters) and later summed up in order to obtain a final score (out of hundred) which aided to obtain development parameters.

\section{Total Score $=\left(\right.$ Normalized $\left.V_{p, i, s}\right) *($ Allotted Weight $)----(g)$}

Figure 5 shows the overall methodology followed while carrying out the work.

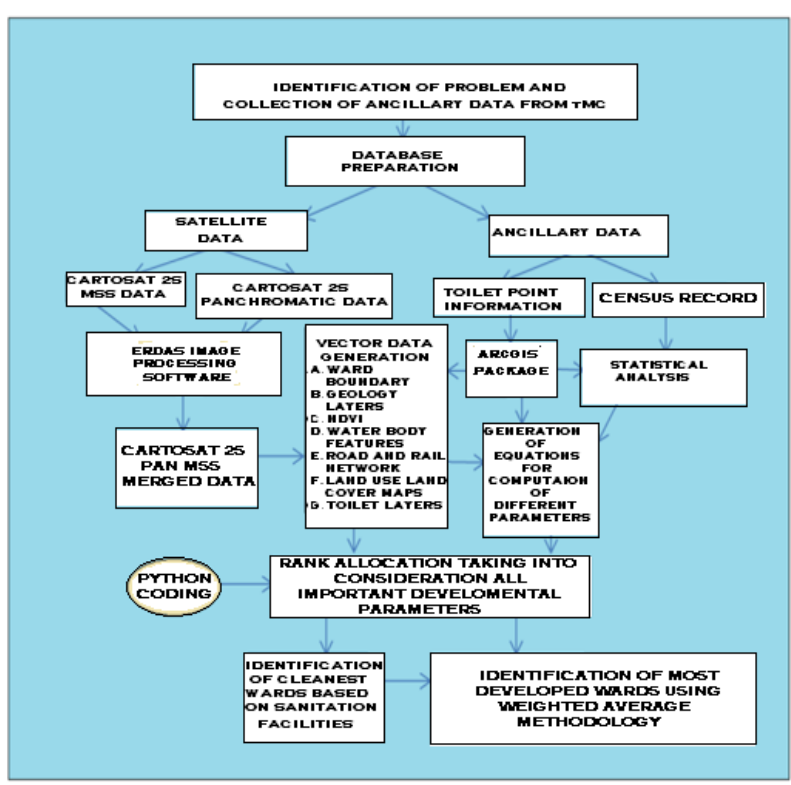


Figure 5: Methodology Flowchart

\section{RESULTS AND DISCUSSIONS}

In the present research work data collected through primary and secondary sources were processed in ArcGIS for geospatial database generation. The parameters such as Population, Area, Built-Up and Households obtained from the generated spatial database helped in deriving following results and achieving desired objectives.

\subsection{Population Data}

Based on the data given by Trichy Municipal Corporation, the ward-wise population was given rankings, the classification range of which is given below:

1. Population Record 2001: Maximum and minimum populations recorded were 19201 (ward no 56) and 6527 (ward no 34) respectively

2. Population Record 2011: Maximum and minimum populations recorded were 27468 (ward no 56) and 6594 (ward no 51) respectively.

3. Population Record 2015: Maximum and minimum populations recorded were 30206 (ward no 56) and 7100 (ward no 24) respectively.

\subsection{Population Densities}

Population Density: It is obtained by dividing the population by the land area.

$$
\text { Population density }=\frac{\text { Population }}{\text { Area in Sq.Kms }}
$$

The population densities were obtained for all the above population data, the rankings of which were given accordingly thereafter

1. Population Density 2001: Maximum and minimum population densities recorded were $\mathbf{8 7 1 5 6}$ (ward no 22) and 897(ward no 39) respectively.

2. Population Density 2011: Maximum and minimum population densities recorded were 88015 (ward no 22) and 913(ward no 39) respectively.

3. Population Density 2015: Maximum and minimum population densities recorded were 88793(ward no 22) and 932(ward no 39) respectively.

\subsection{Built-Up Population Densities}

Built-up Population Density: It is obtained by dividing the Population Densities by the built-up area. The built-up densities were obtained for all the above population data, the rankings of which were given accordingly thereafter.

$$
\text { Built-up Pop density }=\frac{\text { Population Density }}{\text { Builtup Area in Sq.Kms }}
$$

1. Built-up Pop Density 2001: Maximum and minimum built-up densities recorded were 241704(ward no 32) and 2219(ward no 1) respectively.

2. Built-up Pop Density 2011: Maximum and minimum built-up densities recorded were 428721(ward no 32) and 3052(ward no 1) respectively.

3. Built-up Pop Density 2015: Maximum and minimum built-up densities recorded were 373533(ward no 32) and 3413(ward no 1) respectively.

4. Percentage of Built-up area: Maximum and minimum percentage of built-up area recorded were 100(ward no 3) and 1(ward no 32) respectively

\subsection{Households}

Maximum and minimum households as of provided data recorded were 7009 (ward no 38) and 1583 (ward no 13) respectively.

\subsection{Normalized Difference Vegetation Index}

NDVI is a measure of the percentage of greenery present in an area. It is given by the formula:

$$
\mathbf{N D V I}=\frac{\mathbf{N I R}-\mathbf{R}}{\mathbf{N I R}+\mathbf{R}} \text { where, } \mathrm{NIR}=\text { Near Infrared, } \mathrm{R}=\text { Red }
$$

Maximum and minimum NDVI percentage recorded were 91.405 (Ward No. 65) and 4.793 (Ward No. 29) respectively.

\subsection{Road and Rail Network}

Road and rail networks are a major portion of development. Maximum and minimum road lengths of the city recorded were 51.039 sq. kms. (Ward no 38) and 0 sq.kms. (presence of un-pitched roads only) (Ward no 65) respectively.

\subsection{Adequacy of Toilets}

The presence of public toilets is one of the most important parameters of Swachh Bharat Mission. For throwing light on this, analysis was done to find out the number of toilets present in the city. The rankings for the toilets were given based on the number of toilets that already exist in the city. Later the required number of toilets to be built was computed based on different parameters and compared with the present data to find the adequacy of toilets. After all of the above calculations the following records were generated which represent the toilets that are already existing, the requirement based on increased population and forecasts based on tourism and slum requirements. These are represented in the tabular format below:

Table 1: Adequacy of Toilets

\begin{tabular}{|c|c|c|c|}
\hline $\begin{array}{l}\text { Zone } \\
\text { Numbers }\end{array}$ & $\begin{array}{l}\text { Existing number } \\
\text { of Public Toilets }\end{array}$ & $\begin{array}{l}\text { Required } \\
\text { Public Toilets }\end{array}$ & $\begin{array}{l}\text { Projected } \\
\text { Public Toilets }\end{array}$ \\
\hline 1 & 89 & 236 & 328 \\
\hline
\end{tabular}




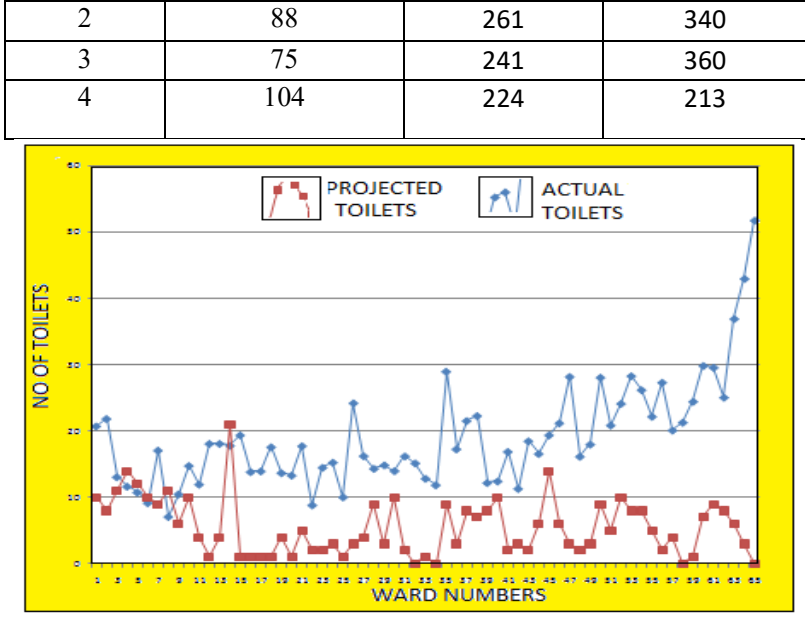

Fig 6: Adequacy analysis of Public Toilets in Each Ward

The results of the public toilet adequacy represented in Figure 6 drew us to a conclusion that ward number $10,4,45$ and 14 are the wards having the most number of toilets. Ward numbers 34, 56 and 64 are the wards having very less toilets and are needed to be improved critically

\subsection{Development Index for the city}

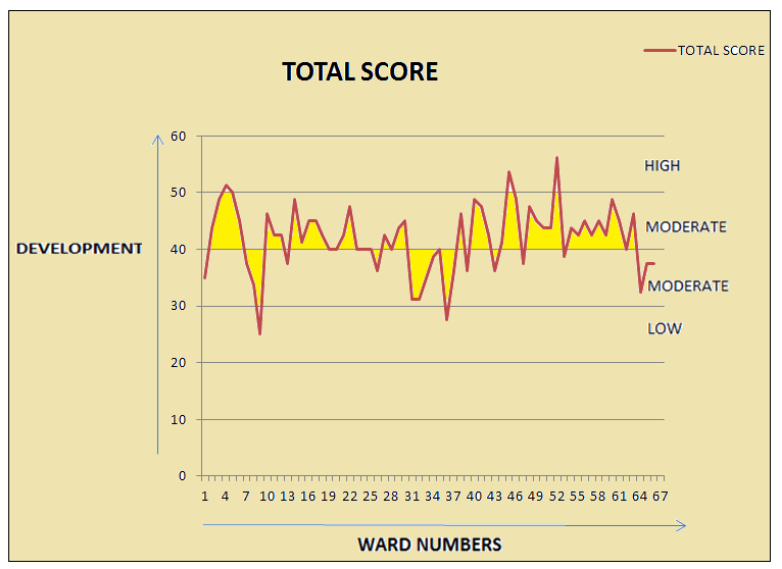

Figure 7: Best ranked wards

After having carefully observed and analyzed the data using the above mentioned methods, we have assessed that Trichy is a clean city in overall but some wards in the city still needs to be improved critically. As per the analysis, the wards were classified under three categories viz., high, moderate and low developed wards as displayed in Figure 7.

Ward Number 4, 45 and 52 was identified with more area under greenery, built-up, transportation network and good sanitation facilities. These wards have therefore been reflected in the total scores as highly developed.

On the contrary, Ward Number 9 and 36 was identified with inadequate green cover, very less built-up, poor infrastructure facilities viz., public toilets and transportation network. Hence, these wards are reflected as poorly developed.

Table 2 shows the development index of the wards, pictorial representation of which is shown in Figure 8.

Table 2: Development Statistics

\begin{tabular}{|c|c|}
\hline DEVELOPMENT CATEGORY & WARDS \\
\hline HIGH & 3 \\
LOW & 2 \\
MODERATE & 61 \\
\hline
\end{tabular}

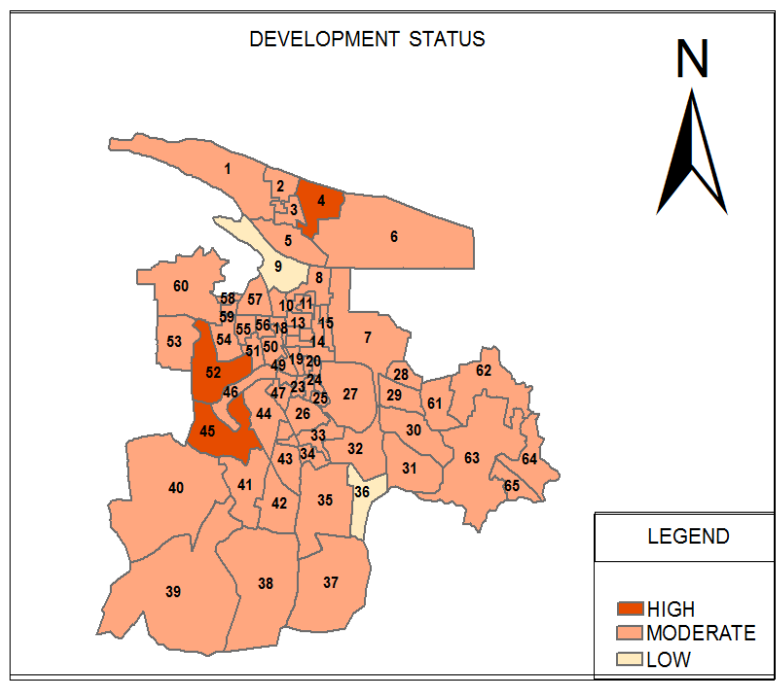

Figure 08: Map displaying the Development Status of wards

\section{CONCLUSIONS}

Health and Sanitation is needed to be well maintained by every person to achieve a clean and a healthy earth. There is no doubt that India has achieved a major milestone in improving the living conditions by improvising Swachh Bharat Abhiyaan and can be improved to a good extent in the future. The above analysis clearly demonstrates abilities of GIS and Remote Sensing playing a major role in assessing sanitation facilities as well as for monitoring the development of the city. The study however shows us a glimpse of the sanitary condition as well as development of the city. Wards that are classified under worst category need more improvement as they reflect very poor sanitation and development statistics. The city is still lacking sanitation facilities due to rapid increase in population and migration to the city. Hence, proper planning is still needed to be done. However ground verification and interaction with officials and people need to be carried out to validate the results.

\section{FUTURE SCOPE OF STUDY}

Swach Bharat Abhiyaan is one of a major success of the Government of India in successfully improving the living standards, health and sanitation amongst citizens of different states of India. But not to miss the fact that this target is 
achieved by political participation rather than planning techniques. A lot of success for the country is yet to be achieved. This can be achieved by proper planning methods and giving suggestions, keeping records and monitoring them and many more things. All these can be achieved by using spatial planning tools and programming languages. Still lot of work is left to be done in this field such as suggesting proper waste dumping sites, redesigning of roads and extremely crowded areas, implementation of rain water harvesting systems and many more. The use of Remote Sensing and GIS can be major tools in achieving all desired results. Spatial Technology when combined with Big Data Analytics can become a major step in achieving such results

\section{ACKNOWLEDGEMENT}

Authors are thankful to Director, NRSC and CGM RRSCs for their encouragement. We thank Trichy Municipal Corporation for providing necessary data for carrying out the research. We extend our sincere thanks to the technical as well as nontechnical staff of RRSC-S for providing required support during the course of the work.

\section{REFERENCES}

\subsection{JOURNAL PAPERS AND CONFERENCES}

1. Tiwari, Surendra Kumar(2014). "To Study Awareness of a National Mission: Swachh Bharat: Swachh Vidyalaya in The Middle School Student of Private And Public Schools", Indian Journal of Research, Volume: 3, Issue: 12

2. Evne,K.(2014). "Swachh Bharat Mission and Dalit Community Development in India", International Journal Of Creative Research Thoughts, Volume 2, Issue 9

3. Badra and Sharma, S (2015). "Management Lessons from Swachh Bharat Mission", International Journal of Advance Research in Science and Engineering, Vol. No.4, Special Issue (01)
4. Subbarao,Venkata P. and Somasekhar, S.(2015), "Swachh Bharat: Some Issues and Concerns", International Journal of Academic Research ISSN: 2348-7666 : Vol.2, Issue-4(4)

5. Thakkar, Priyanka (2015). "Swachh Bharat [Clean India] Mission - An Analytical Study", Renewable Research Journal, ISSN 2321-1067, Volume 3 Issue 2 Page 168

6. Munier, Nolberto (2005), "Road To A Better Future:Introduction To Sustainability", ISBN-978-14020-3558-6, DOI-10.1007/1-4020-3558-6

7. Singh, K.(2015) "How to Make Your Garbage Green in Two Easy Steps" The CSR Journal, Vol. 3, No. 5 http://thecsrjournal.in/how-to-make-your-garbage-green-in-twoeasy-steps/

\subsection{NEWS PAPERS AND ONLINE SOURCES}

1. Earth 911. Trash Planet: India. (2009) http://www.earth911.com/earth-watch/trash-planet-india/

2. Clean India Journal,(2015)"Creating Cleanliness" http://www.cleanindiajournal.com/creating-cleanliness/

3. Rukmini, S. (2014) The Hindu. Modi Launches "My Clean India" Campaign.

http://www.thehindu.com/news/national/modi-launches-mycleanindiacampaign/article6468047.ece

4. Phukan, S.R. (2014) Swachh Bharat Abhiyaan: Making India Clean \& More. http://www.mapsofindia.com/myindia/society/swachh-Bharat-Abhiyaan-making-india-clean$\underline{\text { more }}$

5. Sharma, Y. (2015) Swachh Bharat Abhiyaan: Government Builds 7.1 Lakh Toilets in January. http://articles.economictimes.indiatimes.com/2015-0217/news/59232518 1 india-opendefecation-swachh-BharatAbhiyaan-toilets/

6. Coates, S. and Dulk, D.C. (2014) Elsevier Connect. Making a Stink: @UNICEFIndia Seeks to End Open Defecation. http://www.elsevier.com/connect/unicef-india-campaigns-toend-open-defecation 